\title{
Comparative maturation of cynomolgus monkey oocytes in vivo and in vitro
}

\author{
Hang Yin*1, Diane M Duffy ${ }^{2}$ and Roger G Gosden ${ }^{1}$
}

Address: ${ }^{1}$ The Jones Institute for Reproductive Medicine, Department of Obstetrics and Gynaecology Eastern Virginia Medical School, Norfolk, VA 23507, USA and 2Department of Physiological Sciences, Eastern Virginia Medical School, Norfolk, VA 23507, USA

Email: Hang Yin* - Hay2003@med.cornell.edu; Diane M Duffy - Duffydm@evms.edu; Roger G Gosden - rgg2004@med.cornell.edu

* Corresponding author

Published: 04 April 2006

Reproductive Biology and Endocrinology 2006, 4:14 doi:10.1 186//477-7827-4-14

This article is available from: http://www.rbej.com/content/4/1/14

(c) 2006 Yin et al; licensee BioMed Central Ltd.

This is an Open Access article distributed under the terms of the Creative Commons Attribution License (http://creativecommons.org/licenses/by/2.0), which permits unrestricted use, distribution, and reproduction in any medium, provided the original work is properly cited.
Received: 28 February 2006

Accepted: 04 April 2006

\begin{abstract}
Background: In vitro maturation (IVM) of oocytes followed by fertilization in vitro (IVF) and embryo transfer offers an alternative to conventional IVF treatment that minimises drug administration and avoids ovarian hyperstimulation. However, the technique is less efficient than maturation in vivo. In the present study, a non-human primate model was used to address the hypothesis that the number of oocytes is increased and their nuclear and cytoplasmic maturity after IVM are improved when maturation is initiated in vivo by priming with hCG.
\end{abstract}

Methods: Young, adult cynomolgus monkeys were given recombinant human (rh) gonadotropins to stimulate the development of multiple follicles, and oocytes were aspirated $0,12,24$, or $36 \mathrm{~h}$ after injection of an ovulatory dose of rhCG. The nuclear status of oocytes was determined at the time of recovery and after culture for a total elapsed time of 40-44 hours after hCG.

Results: Priming with hCG significantly increased the number of oocytes harvested, especially after delaying aspiration for $24 \mathrm{~h}$ or longer. Nuclear maturation after the full period in culture was also enhanced by priming: $71.5,83.6$, and $94.6 \%$ of oocytes collected at 0,12 , and $24 \mathrm{~h}$ hCG had progressed to MII by the end of the culture period, compared to $87.8 \%$ of oocytes that were retrieved at $36 \mathrm{~h}$. A large proportion of oocytes reaching the MIl stage had either or both abnormal spindles (>40\%) and misaligned chromosomes (>60\%), judging by immunofluorescence microscopy, but these abnormalities were independent of culture time. The mitochondria were evenly distributed throughout the cytoplasm at all stages of maturation. Importantly, there was no microscopic evidence that the duration of culture had any injurious effects on the cells.

Conclusion: In conclusion, the evidence supports this non-human primate as a model for human IVM and the practice of priming with hCG to promote developmental potential.

\section{Background}

In vitro maturation (IVM) is a culture technology that enables a high proportion of fully-grown oocytes at the germinal vesicle $(\mathrm{GV})$ stage to reach metaphase II (MII). When mature, the oocytes may be fertilised in vitro and they become available for transfer to a physiologically synchronised reproductive tract after reaching the cleavage or blastocyst stage. While pregnancy rates after IVM can be impressively high in some laboratory and farm ani- 
mal species [1-6], applications for human reproductive medicine are just now gathering momentum.

The first human birth reported after IVM was achieved after controlled ovarian stimulation [7]. More than two decades later, several hundred live births have resulted from IVM-IVF, often in cycles lacking FSH stimulation rather than rescuing immature gametes after conventional ovarian stimulation, as in the case above [8]. There is still no standard protocol for IVM, but protocols normally avoid the use of FSH in the interests of simplifying treatment, reducing drug administration and avoiding ovarian hyperstimulation syndrome in women with polycystic ovaries [9]. A single injection of 10,000 IU hCG has been advocated for initiating maturation in vivo before transferring oocytes to culture, because it increased the number and quality of the gametes obtained [10-12]. Pregnancy and implantation rates for IVM-IVF are, however, generally lower than after conventional IVF treatment in the same centers, and the incidence of miscarriage is usually higher. This experience has encouraged the practice of transferring on average slightly more embryos to compensate for the lower pregnancy rates, but this unfortunately raises the risk of multiple pregnancy. Optimal protocols for recovery and culture are needed to increase the success of IVM with the ultimate aim of single embryo transfer.

Progress with IVM has been hindered by the scarcity of suitable human oocytes for research. A non-human primate model is highly desirable because the physiology of the menstrual cycle and embryology are more comparable to humans than other model species. Schramm \& Bavister [13] reported the first simian blastocysts created after IVM, and four years later the first live-born infant was announced by the same center [14]. Several culture media have been used in humans and monkeys, and the rates of oocyte maturation to MII have been in the range $60-80 \%$ in most reports $[7,15-20]$. More disappointingly, the rates of blastocyst formation and pregnancy were only $10-40 \%$ and $15-30 \%$, respectively, implying that developmental competence was impaired [17-19,21]. It was not clear whether the excess reproductive wastage was due to chromosomal aberrations, which are common in human oocytes. The ability to undergo nuclear maturation is necessary but not sufficient for fertility, which requires faithful congression of chromosomes on the spindle equator and other less well-understood changes that have been collectively called "cytoplasmic maturation". Nevertheless, it is evident that culture conditions are not yet able to faithfully mimic the intrafollicular environment [22].

Accordingly, oocytes that initiated maturation in vivo before transfer to culture should produce better quality gametes. There is bi-directional flow of signals between oocytes and granulosa cells via trans-zonal projections and the extracellular fluid [23]. Cellular stress resulting from manipulation, changing environments and mechanical injury to delicate processes (especially during the early hours of maturation) could impair the balanced coordination of nuclear and cytoplasmic maturation [24]. We further propose that the aforementioned benefit of hCG priming of human ovaries is due to the initiation of physiological events associated with a critical period of maturation before oocytes are exposed to sub-optimal conditions in vitro. This hypothesis was tested by collecting cynomolgus monkey oocytes before and at specific times up to $36 \mathrm{~h}$ after hCG treatment. In an ideal model, the quality of oocytes would be as susceptible as in humans to errors generated during meiosis $[25,26]$. Although rarely studied, cytogenetic errors have been reported in monkey oocytes, supporting their value as a model for human reproductive biology and technology [27]. The integrity of the spindle apparatus and the distribution of mitochondria have been studied here, because they provide indications of oocyte competence after exposure to culture conditions [28-31].

\section{Materials and methods Animals}

Adult female cynomolgus monkeys (Macaca fascicularis) aged $8.5 \pm 0.3$ years were studied under the approval of the Institutional Animal Care and Use Committee at the Eastern Virginia Medical School and in accordance with the NIH Guide for the Care and Use of Laboratory Animals. Monkey chow (Agway, Elizabeth City, NJ) was provided twice per day and water was available ad libitum. Animals were maintained as social pairs with a light:dark cycle of $12: 12 \mathrm{~h}$ at $23^{\circ} \mathrm{C}$. The animals had regular menstrual cycles and were inspected daily for signs of the onset of menstruation.

\section{Ovarian stimulation and oocyte collection}

A total of 39 ovarian stimulation cycles from 18 animals was performed. Each animal was stimulated from 1 to 3 cycles with at least two months intervals. A standard protocol for controlled ovarian stimulation was used to obtain multiple oocytes [32]. Blood samples were collected by femoral venepuncture under ketamine chemical restraint. Stimulation started within 1-3 days after initiation of menses by administering 60IU recombinanthuman FSH i.m. (r-hFSH, Serono Reproductive Biology Institute, Rockland, MA) twice daily for 6-8 days, followed by $60 \mathrm{IU}$ r-hFSH and $45 \mathrm{IU}$ r-hLH twice daily for 2 days to stimulate multiple follicle growth. The GnRH antagonist, Antide, was administered daily $(0.5 \mathrm{mg} / \mathrm{kg}$ body weight in propylene glycol: water (1:1); Serono) to prevent an endogenous LH surge. Follicle development was monitored by serum oestradiol concentrations and ultrasonography. Follicle aspiration was performed during aseptic surgery with a syringe and a 23 g needle by 
either laparotomy or laparoscopy on anaesthetised monkeys either without hCG priming (recorded as $0 \mathrm{~h}$ ) or 12, 24 , or $36 \mathrm{~h}$ after receiving 1000 IU r-hCG i. m. [33]. In the laboratory, follicular aspirates were diluted in Talp-Hepes medium containing $0.3 \%$ bovine serum albumin (BSA), and oocytes were mechanically removed with the aid of a dissecting microscope. Only oocytes that appeared morphologically normal and surrounded by cumulus cells were studied in culture.

\section{Oocyte culture}

The oocytes were cultured in $50 \mu$ droplets of M-199 medium (Gibco Cell Culture, Invitrogen, Carlsbad, CA) under a layer of embryo-tested mineral oil (Sigma) at $37^{\circ} \mathrm{C}$ in an atmosphere of $5 \% \mathrm{CO}_{2}$ and $95 \%$ air for a total 40-44 h post-hCG. This time was chosen because oocytes are routinely retrieved $36 \mathrm{~h}$ after hCG in patients, and IVF or (more typically) ICSI is performed at least $4 \mathrm{~h}$ afterwards. The medium was supplemented with $10 \%$ fetal bovine serum (Hyclone, Logan, UT), $1 \mu \mathrm{g} / \mathrm{ml}$ oestradiol$17 \beta$ (Sigma) and $75 \mu \mathrm{IU} / \mathrm{ml}$ of both r-hFSH and r-hLH (Serono). The stage of maturation was evaluated under an inverted phase contrast microscope based on the degree of cumulus expansion and emission of the first polar body, confirming that oocytes had reached MII. Oocytes with a GV nucleus were assumed to be still at prophase I, and those with neither a nucleus nor a polar body were classified as GVBD (germinal vesicle breakdown) and presumed to be at the metaphase I (MI) stage. At the time of retrieval, very few oocytes appeared dark and/or contracted (presumably degenerated) or contained pronuclei or had cleaved spontaneously.

\section{Immunocytochemistry of spindles and mitochondria}

The cumulus cells were removed after brief exposure to 30 IU/ml hyaluronidase (Sigma) in M-199 medium under oil. For spindle analysis, oocytes were fixed according to a protocol modified from Baka et al. [34]. Oocytes were fixed in microtubule-stabilising buffer containing 3.7\% formaldehyde and $0.5 \%$ Triton X-100 (Sigma) at $37^{\circ} \mathrm{C}$ for $30 \mathrm{~min}$. To reduce background cytoplasmic staining, fixed oocytes were incubated in a blocking solution overnight at $4{ }^{\circ} \mathrm{C}$, which containing $2 \%$ BSA (Sigma), 2\% Carnation powdered skim milk (Nestle USA, Glendale, CA), 2\% normal rabbit serum (Sigma), $0.1 \mathrm{M}$ glycine (Sigma) and $0.01 \%$ Triton X-100 in PBS. For spindle staining, oocytes were incubated for $1 \mathrm{~h}$ at $37^{\circ} \mathrm{C}$ with a mouse monoclonal anti- $\alpha$-tubulin antibody (Sigma) diluted 1:100 in PBS containing $0.1 \%$ BSA and $0.02 \%$ sodium azide (Sigma). They were then incubated in blocking solution for another hour. To visualise spindles, oocytes were stained with rabbit anti-mouse immunoglobulin (IgG) conjugated with fluorescein (FITC; Sigma). Chromosomes were stained with $10 \mu \mathrm{g} / \mathrm{ml} \mathrm{4',6'-diamidino-2-phenylindole}$ (DAPI; Sigma) in PBS for $15 \mathrm{~min}$ at room temperature. After mounting in glycerol:PBS $(9: 1, \mathrm{v}: \mathrm{v})$ containing 100 $\mathrm{mg} / \mathrm{ml}$ of 1,4-diazabicyclo(2.2.2)-octane (DABCO; Sigma), the antifading reagent, they were examined with a Nikon fluorescence microscope.

To examine the distribution of mitochondria, oocytes were fixed in $3.7 \%$ formaldehyde for $20 \mathrm{~min}$ at room temperature after removing cumulus cells using hyaluronidase $(30 \mathrm{IU} / \mathrm{ml})$. They were stained in $140 \mathrm{nM}$ MitoTracker $^{\circledR}$ Red 580 (Molecular Probes, Eugene, OR) for $20 \mathrm{~min}$ at room temperature. The DNA was stained with DAPI. Oocytes were mounted on slides as described above, and the distribution of mitochondria was analysed by standard fluorescence and confocal microscopy.

\section{Statistical analysis}

Comparisons between groups of oocytes were performed using Chi-square, Fisher's exact test and ANOVA with Tukey-Kramer Multiple Comparison Test as a post test. Results were considered significantly different if $\mathrm{p} \leq 0.05$.

\section{Results}

A total of 424 oocytes were retrieved from 18 animals, with a mean number of oocytes at 10.9 per animal and per cycle. The numbers of oocytes recovered increased significantly with time elapsed after the injection of hCG (Table 1). At retrieval, the developmental stage of the oocytes could be clearly defined by the presence or absence of the GV nucleus and/or polar body. The large majority in the group that did not receive hCG priming (i.e. $0 \mathrm{~h}$ ) remained at the GV stage (93.2\%). The proportions at the

Table I: Number and developmental stage of oocytes at retrieval at different times after hCG injection.

\begin{tabular}{cccccc}
\hline $\begin{array}{c}\text { Time of oocyte retrieval post-hCG } \\
\text { (time in culture) (h) }\end{array}$ & Number of oocyes & Oocytes per cycle* & GV(\%) & GVBD(\%) & MII(\%) \\
\hline $0(40-44)$ & 147 & $8.2 \pm 0.8$ & $137(93.2)$ & $5(3.4)$ & $5(3.4)$ \\
$12(38-42)$ & 74 & $9.3 \pm 1.1$ & $61(82.4)$ & $11(14.9)$ & $2(2.7)$ \\
$24(16-20)$ & 80 & $13.3 \pm 3.8$ & $6(7.5)$ & $74(92.5)$ & $0(0)$ \\
$36(4-8)$ & 123 & $17.6 \pm 2.3 * *$ & $4(3.3)$ & $11(8.9)$ & $108(87.8)$ \\
\hline
\end{tabular}

GV: germinal vesicle, GVBD: germinal vesicle breakdown, MII: metaphase II *Mean \pm SEM. ANOVA was performed, and **: $\mathrm{P}<0.0 \mathrm{I}$ compared with group at $0 \mathrm{~h}, \mathrm{P}<0.05$ compared with the group at $12 \mathrm{~h}$ 
Table 2: Number of oocytes resuming development in culture and analysed $\mathbf{4 0 - 4 4 ~} \mathrm{h}$ after hCG priming and variable times in culture

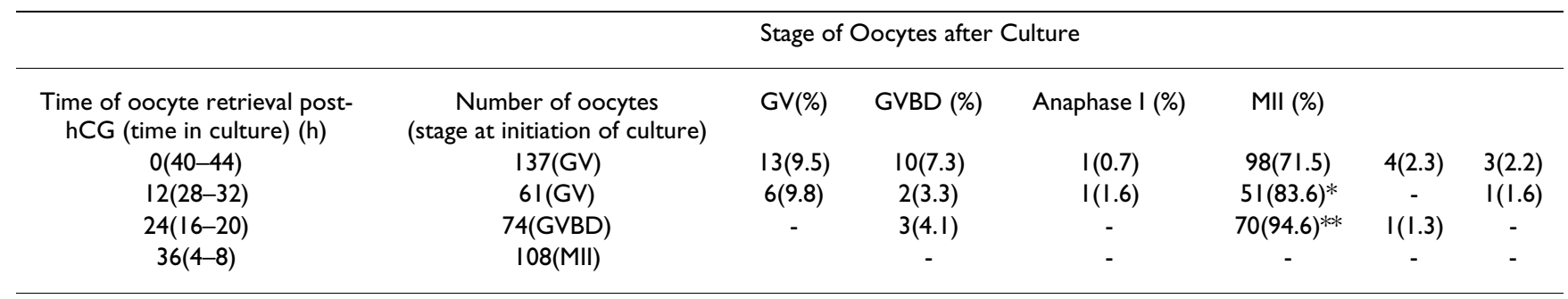

Fisher's exact test was performed. $* \mathrm{P}<0.05$; and $* * \mathrm{P}<0.001$ compared with $0 \mathrm{~h}$ group

GV stage declined significantly as the interval between hCG and oocyte recovery increased, with a corresponding rise in those progressing to the GVBD stage (Table 1). Between 12-24 h post-hCG, more than half of the oocytes were scored as GVBD. Only $2.3 \%$ of the oocytes (7/301) had reached the MII stage before $36 \mathrm{~h}$, and these were likely to have been in atretic follicles. However, by $36 \mathrm{~h}$ after hCG priming, the majority of oocytes $(87.8 \%)$ were MII at aspiration and presumably ripe for fertilization.

After transfer to culture, most GV and GVBD oocytes resumed maturation towards the MII stage (Table 2). The smallest percentage reaching MII was in the group that was cultured for longest ( 0 h post-hCG), i.e., only 98/137 $(71.5 \%)$ reached MII. In the $12 \mathrm{~h}$ post-hCG group, which were in culture for a correspondingly shorter time, there were initially $61 \mathrm{GV}$ oocytes, of which 55 underwent GVBD during the subsequent $28-32 \mathrm{~h}$ in culture; and 51 of total (83.6\%) finally reached MII. A majority of oocytes collected $24 \mathrm{~h}$ post-hCG were at the GVBD stage and went forward during the 16-20 h culture period to the MII stage (94.6\%). Oocytes recovered from follicles $36 \mathrm{~h}$ post-hCG had $87.8 \%(108 / 123)$ reached the MII stage without undergoing parthenogenetic activation or showing any obvious signs of degeneration. On the other hand, in total of five oocytes and another four that were cultured for longer period underwent these respective changes (Table 2). It was unlikely that by extending the culture period for a few hours the proportion of mature oocytes would have increased in either the 0 or $12 \mathrm{~h}$ post-hCG groups, because most immature gametes were still at the GV stage (Table 2). All five oocytes retrieved at the GVBD stage without the benefit of hCG priming, and 10 of 11 GVBD oocytes collected at $12 \mathrm{~h}$ completed maturation after transfer to culture. But only one of the six GV oocytes collected at $24 \mathrm{~h}$ post-hCG developed to GVBD, and the rest remained arrested. Among the GV oocytes collected 36 h post-hCG and cultured for $4-8 \mathrm{~h}$, only 1 of 4 underwent GVBD, and 4 of 11 at GVBD arrested at anaphase I. It appeared, therefore, that there is little to gain by culturing oocytes after hCG priming, either because the oocytes are meiotically incompetent or culture conditions are suboptimal. Overall, the data indicated that the longer the period of maturation in vivo (or the shorter the culture period) the greater the harvest of mature gametes. Nevertheless, a respectable proportion of $>70 \%$ of GV oocytes reached nuclear maturity, even in the group cultured for the maximum time.

Normally, MII monkey oocytes have a bipolar, barrelshaped spindle with chromosomes aligned uniformly at the equator plate (Figure 1A, a). Various abnormal forms were observed in this study, including asymmetric, tripolar and depolymerised spindles, as well as displaced, lagging and disorganised chromosomes. There were more oocytes with abnormal chromosome alignments than abnormal spindles, and only $23 \%(65 / 280)$ of oocytes were normal in both respects. The high incidence of anomalies was striking: less than half of the oocytes had a normal spindle and only a third had well-aligned chro-

Table 3: Spindle structure and chromosome alignment in MIl oocytes analysed 40-44 h after hCG priming and variable times in culture

\begin{tabular}{|c|c|c|c|c|c|}
\hline \multirow{2}{*}{$\begin{array}{l}\text { Time of oocyte } \\
\text { retrieval post-hCG } \\
\text { (time in culture) }(\mathrm{h})\end{array}$} & \multirow[t]{2}{*}{ Number of oocytes } & \multicolumn{2}{|c|}{ Spindle structure (\%) } & \multicolumn{2}{|c|}{ Chromosome alignment (\%) } \\
\hline & & Normal & Abnormal & Normal & Abnormal \\
\hline $0(40-44)$ & 89 & $44(49.4)$ & $45(50.6)$ & $30(33.7)$ & $59(66.3)$ \\
\hline $12(28-32)$ & 44 & $25(56.8)$ & $19(43.2)$ & $15(34.1)$ & $29(65.9)$ \\
\hline $24(16-20)$ & 58 & $18(31.0)$ & $40(69.0)^{*}$ & $21(36.2)$ & $37(63.8)$ \\
\hline $36(4-8)$ & 89 & 40 (44.9) & $49(55.1)$ & $28(31.5)$ & $61(68.5)$ \\
\hline
\end{tabular}

Fisher's exact test was performed. $* \mathrm{P}<0.05$ compared with groups at 0 and $12 \mathrm{~h}$ 

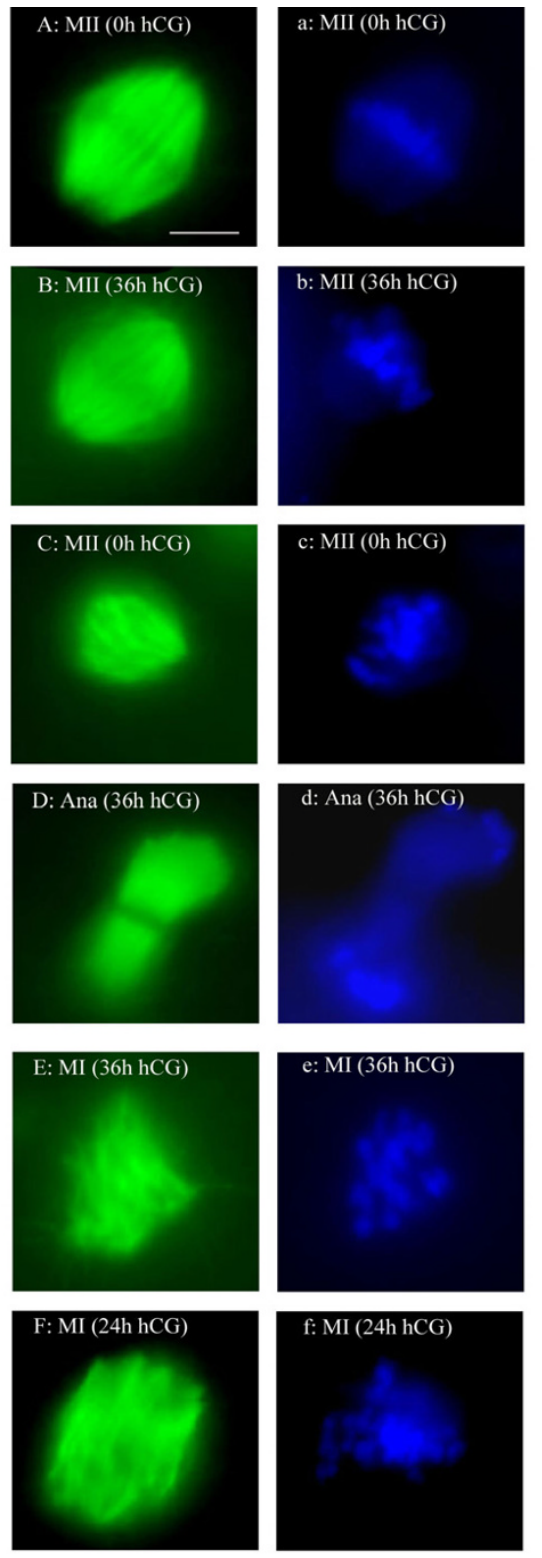

Figure I

Spindle formation and chromosome alignment in oocytes. A, $B, C, D, E$ and $F$ showing spindles in green after staining with an anti $\alpha$-tubulin antibody, and a, b, c, d, e and f showing chromosomes in blue after DAPI staining (chromatin). Normal bi-polar spindle and well-aligned chromosomes were present in MIl oocytes $(0 \mathrm{~h})$ after $40-44 \mathrm{~h}$ entirely in culture ( $A$ and $\mathrm{a}$ ), or in an oocyte $36 \mathrm{~h}$ post-hCG (B and b); asymmetric spindle and displaced chromosomes around the spindle equator plate in a MII oocyte after $40-44 \mathrm{~h}$ in culture (C and c); an oocyte retrieved at $36 \mathrm{~h}$ post-hCG was arrested at anaphase I ( $D$ and d); $M I$ oocyte retrieved $36 \mathrm{~h}$ post-hCG possessed abnormal spindles and disorganised chromosomes ( $E$ and e); a cultured oocyte retrieved at $24 \mathrm{~h}$ post-hCG was arrested at GVBD with an abnormal spindle and disorganised chromosomes ( $F$ and $f$ ). Magnification bar in $(A)=5 \mu \mathrm{m}$ mosomes. There were apparently fewer normal spindles at $24 \mathrm{~h}$, and the difference was marginally significant compared to the data at $0 \mathrm{~h}(\mathrm{p}=0.040)$ and $12 \mathrm{~h}(\mathrm{p}=0.015$, Table 3). None of the oocytes arrested at the GVBD stage after culture in any of the experimental groups had a normal MI spindle and chromosome congression at the equator plate (Figure 1F, f). There were four oocytes with abnormal, tripolar spindles, which may be an indication of defective cellular polarity.

A total of 99 oocytes at GV, GVBD and MII stages were stained for mitochondria (Table 4). These organelles were evenly distributed throughout the cytoplasm of the cells. There was no obvious congregation of mitochondria around the GV nucleus or the spindle of MI and MII oocytes (Figure 2), and their distribution did not differ between GV and MII stages or in relation to time in culture.

\section{Discussion}

This study has demonstrated that the timing of oocyte collection after stimulating cynomolgus monkey ovaries with hCG has a striking effect on the prospects for IVM. The main effect was on the numbers of oocytes recovered, a larger harvest being obtained when the collection was delayed after hCG priming. This result can be accounted for by a lower efficiency of aspirating immature oocytes with unexpanded cumulus masses. The efficiency of collection from unstimulated human ovaries has been improved by curetting follicles with a modified needle and a lower aspiration pressure [15]; technical modifications may also improve oocyte harvests in unstimulated monkey ovaries.

These data confirmed that the time taken for monkey oocytes to reach MI and MII are comparable to humans [35-37]. More than $12 \mathrm{~h}$ was required to undergo GVBD, compared with only 2-4 h in the mouse, and MII was not reached until $36 \mathrm{~h}$, compared to $12-16 \mathrm{~h}[38,39]$. The data indicated that the proportion of oocytes becoming mature was significantly increased after hCG priming (Table 2). Without continuous observation in vitro, it was not possible to assess variations between gametes in the time taken to mature, which ranges from $24-48 \mathrm{~h}$ for

Table 4: Number and developmental stage of oocytes stained to reveal the distribution of mitochondria 40-44 $\mathrm{h}$ after priming with hCG and variable times in culture

\begin{tabular}{ccccc}
\hline $\begin{array}{c}\text { Time of oocyte retrieval post- } \\
\text { hCG (time in culture) }(\mathrm{h})\end{array}$ & $\begin{array}{c}\text { Number of } \\
\text { oocytes }\end{array}$ & GV & GVBD & MII \\
\hline $0(40-44)$ & 29 & 10 & 5 & 14 \\
$12(28-32)$ & 25 & 6 & 2 & 17 \\
$24(16-20)$ & 18 & 4 & 2 & 12 \\
$36(4-8)$ & 27 & 3 & 6 & 18 \\
\hline
\end{tabular}



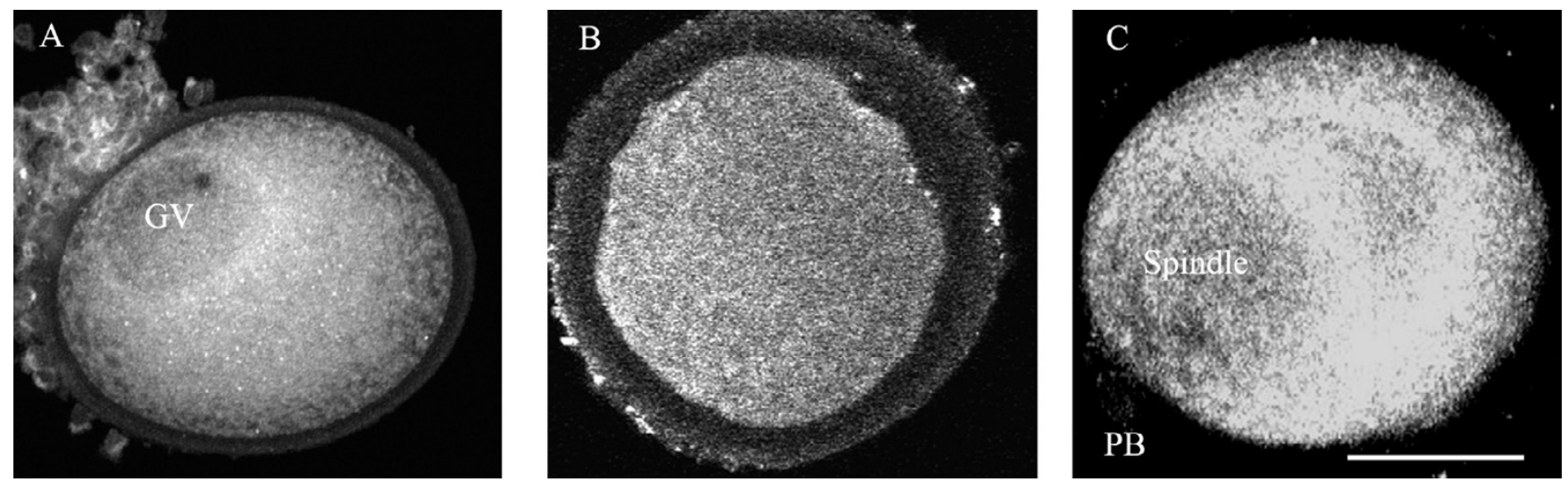

Figure 2

The distribution of mitochondria in oocytes after $40-44 \mathrm{~h}$ in culture ( $0 \mathrm{~h}$ group) and staining with the mitochondrial dye, MitoTracker ${ }^{\circledR}$ Red 580 . A. Mitochondria surrounding the nucleus (GV) in a freshly-retrieved oocyte. B. Oocyte still arrested at GVBD with mitochondria evenly distributed in cytoplasm. C. Oocyte at MII with mitochondria congregated around the region of spindle and in cytoplasm. Magnification bar in (C) $=50 \mu \mathrm{m}$.

human oocytes [15]. Priming with hCG accelerates the maturation of human oocytes in vitro [40,12], but this finding was based on patients with unstimulated polycystic ovaries, and it is not known if this applies to normal ovareis. Overall, human and simian studies appear to be concordant insofar that they reveal that hCG treatment can be beneficial, although the end-points were different.

The number of oocytes available for fertilization and transfer is a key predictor of pregnancy rates after IVM in humans [41]. Although fertilization and progression to the blastocyst stage were not addressed in the present study, our results revealed that a longer post-hCG interval decreased the percentage still at the GV stage, and only $3.3 \%$ were still arrested at $36 \mathrm{~h}$. The intrafollicular environment is evidently more effective at supporting maturation than culture conditions that were based on a formula widely used in humans and domestic animals [42-44]. There are several formulas for human IVM but, with few exception [16], they all contain serum, and efforts to produce an optimal medium, and preferably chemicallydefined, have been thwarted by the lack of research material. Culture medium supplemented with steroids and growth factors, including oestradiol, progesterone, EGF, IGF-1 and VEGF, have been reported to improve maturation and developmental competence in various animal species [45-50]. However, optimal conditions probably vary between species and even at different phases of the 36 $\mathrm{h}$ incubation period, reflecting the evolving physiological state of the preovulatory follicle. The challenge of improving the clinical success rate with IVM is most acute when oocytes are most limiting, as in the case of natural cycles [51] and cancer patients for whom only one harvest may be feasible [52]. Moreover, that challenge would be also beneficial in the case of somatic cell nuclear replacement, especially in non-human primates and human.

Human oocytes often have small, aberrant spindles with unaligned chromosomes whose frequency rises with maternal age $[53,54]$. Since they are prone to meiotic errors [54], it has been suggested that oocytes lack a spindle checkpoint to control the fidelity of the metaphase/ anaphase transition during the first meiotic division [55]. A remarkably high frequency of abnormal spindles and displaced chromosomes was found in the present study, even though the monkeys were only about eight years old, which is long before reproductive senescence in this species [27]. The high association between spindle integrity and chromosome misalignment indicated that spindle morphology is predictive of aneuploidy, as has been demonstrated in rodent models [30], and it is likely that the same relationship holds in primates. Overall, such findings suggest that spindle defects compromise the quality of monkey oocytes, it is important to note that the incidence was not increased with duration of culture in the present study. However, the effects of ovarian stimulation regimes, such as GnRH, FSH, LH and hCG, on spindle formation and chromosome alignment in non-human primate oocytes may be a focus in the future study.

Mitochondria play an essential role in oocyte and embryo metabolism [31]. Spindle assembly and function are likely to be impaired if ATP production is impaired locally or globally within the cell [30], which could arise from mitochondrial DNA deletions and/or rearrangements $[56,57]$. No evidence has yet been published to show a harmful effect of culture on mitochondrial DNA during IVM, although changes observed in the cytoskeleton 
could impact the distribution and, hence, local activity of these organelles $[28,58]$. The distribution of mitochondria varies over time and between species during oocyte maturation and embryo cleavage [28,59-61]. In the present study, the distribution of mitochondria was even throughout the cytoplasm during the process of maturation, confirming an earlier report [62], and was not affected by time in culture. In view of these findings, it is doubtful if the distribution of these organelles can serve as a useful biomarker for developmental competence of monkey oocytes.

Overall, this study affirms the value of the non-human primate model for optimizing IVM protocols in clinical applications. The findings confirmed the hypothesis that initiation of maturation after priming with hCG is beneficial and provided evidence that the high background incidence of potential cytogenetic errors in cynomolgus monkey oocytes is not raised by culture conditions.

\section{Acknowledgements}

This study was supported by EVMS, NIH HD39872 (D.M. Duffy) \& Serono Reproductive Biology Institute.

\section{References}

I. Mattioli M, Bacci ML, Galeati G, Seren E: Developmental competence of pig oocytes matured and fertilized in vitro. Theriogenology 1989, 3 I: I 20 I-I 207.

2. Pavlok A, Motlik J, Kanka J, Fulka J: In vitro techniques of bovine oocyte maturation, fertilization and embryo culture resulting in the birth of a calf. Reprod Nutr Dev 1989, 29:6 I I-666.

3. Czlonkowska M, Eysymont U, Guszkiewicz A, Kossakowski M, Dziak $\mathrm{J}$ : Birth of lambs after in vitro maturation, fertilization, and coculture with oviductal cells. Mol Reprod Dev I991, 30:34-38.

4. Behboodi E, Van Metre DC, BonDurant RH, Anderson GB: Delivery of a live calf after in vitro maturation and fertilization of oocytes obtained from ovaries removed from a moribund cow. J Am Vet Med Assoc 1994, 205: I588-I589.

5. Ptak G, Loi P, Dattena M, Tischner M, Cappai P: Offspring from one-month-old lambs: studies on the developmental capability of prepubertal oocytes. Biol Reprod 1999, 61: I568-I574.

6. Suzuki M, Misumi K, Ozawa M, Noguchi J, Kaneko H, Ohnuma K, Fuchimoto DI, Onishi A, Iwamoto M, Saito N, Nagai T, Kikuchi K: Successful piglet production by IVF of oocytes matured in vitro using NCSU-37 supplemented with fetal bovine serum. Theriogenology 2006, 20:374-86.

7. Veeck LL, Wortham JW Jr, Witmyer J, Sandow BA, Acosta AA, Garcia JE, Jones GS, Jones HW Jr: Maturation and fertilization of morphologically immature human oocytes in a program of in vitro fertilization. Fertil Steril 1983, 39:594-602.

8. Le Du A, Kadoch IJ, Bourcigaux N, Doumerc S, Bourrier MC, Chevalier N, Fanchin R, Chian RC, Tachdjian G, Frydman R, Frydman N: In vitro oocyte maturation for the treatment of infertility associated with polycystic ovarian syndrome: the French experience. Hum Reprod 2005, 20:420-424.

9. Homburg R: Management of infertility and prevention of ovarian hyperstimulation in women with polycystic ovary syndrome. Best Pract Res Clin Obstet Gynaecol 2004, I 8:773-788.

10. Chian RC, Buckett WM, Tulandi T, Tan SL: Prospective randomized study of human chorionic gonadotrophin priming before immature oocyte retrieval from unstimulated women with polycystic ovarian syndrome. Hum Reprod 2000, I 5:165-170.

II. Papanikolaou EG, Platteau P, Albano C, Nogueira D, Cortvrindt R, Devroey P, Smitz J: Immature oocyte in-vitro maturation: clinical aspects. Reprod Biomed Online 2005, I 0:587-592.
12. Son WY, Lee SY, Lim JH: Fertilization, cleavage and blastocyst development according to the maturation timing of oocytes in in vitro maturation cycles. Hum Reprod 2005, 20:3204-3207.

13. Schramm RD, Bavister BD: Development of in-vitro-fertilized primate embryos into blastocysts in a chemically defined, protein-free culture medium. Hum Reprod 1996, I I:I690-1697.

14. Schramm RD, Paprocki AM: Birth of rhesus monkey infant after transfer of embryos derived from in-vitro matured oocytes: short communication. Hum Reprod 2000, I5:24 II-24|4.

15. Trounson A, Wood C, Kausche A: In vitro maturation and the fertilization and developmental competence of oocytes recovered from untreated polycystic ovarian patients. Fertil Steril 1994, 62:353-362.

16. Wynn P, Picton HM, Krapez JA, Rutherford AJ, Balen AH, Gosden RG: Pretreatment with follicle stimulating hormone promotes the numbers of human oocytes reaching metaphase II by in vitro maturation. Hum Reprod 1998, 13:3132-3138.

17. Mikkelsen AL, Smith SD, Lindenberg S: In-vitro maturation of human oocytes from regularly menstruating women may be successful without follicle stimulating hormone priming. Hum Reprod 1999, I4:1847-185I.

18. Mikkelsen AL, Host E, Blaabjerg J, Lindenberg S: Time interval between FSH priming and aspiration of immature human oocytes for in-vitro maturation: a prospective randomized study. Reprod Biomed Online 2003, 6:416-420.

19. Chian RC: In-vitro maturation of immature oocytes for infertile women with PCOS. Reprod Biomed Online 2004, 8:547-552.

20. Schmidt DW, Maier DB, Nulsen JC, Benadiva CA: Reducing the dose of human chorionic gonadotropin in high responders does not affect the outcomes of in vitro fertilization. Fertil Steril 2004, 82:84I-846.

21. Toth TL, Baka SG, Veeck LL, Jones HW Jr, Muasher S, Lanzendorf SE: Fertilization and in vitro development of cryopreserved human prophase I oocytes. Fertil Steril 1994, 6 I:89|-894.

22. Hunter MG: Follicular factors regulating oocyte maturation and quality. Hum Fertil (Camb) 1998, I:69-74.

23. Albertini DF, Combelles CM, Benecchi E, Carabatsos MJ: Cellular basis for paracrine regulation of ovarian follicle. Reproduction 200 I, I 2 I :647-653.

24. Mikkelsen AL, Lindenberg S: Benefit of FSH priming of women with PCOS to the in vitro maturation procedure and the outcome: a randomized prospective study. Reproduction 200I, I 22:587-592

25. Cupisti S, Conn CM, Fragouli E, Whalley K, Mills JA, Faed J, Delhanty JD: Sequential FISH analysis of oocytes and polar bodies reveals aneuploidy mechanisms. Prenat Diagn 2003, 23:663-668.

26. Sanfins A, Plancha CE, Overstrom EW, Albertini DF: Meiotic spindle morphogenesis in in vivo and in vitro matured mouse oocytes: insights into the relationship between nuclear and cytoplasmic quality. Hum Reprod 2004, 1 9:2889-2899.

27. Franco GC, Lucio PS, Parra FC, Pena SD: A probability model for the meiosis I non-disjunction fraction in numerical chromosomal anomalies. Stat Med 2003, 22:2015-2024.

28. Schramm RD, Paprocki AM, Bavister BD: Features associated with reproductive ageing in female rhesus monkeys. Hum Reprod 2002, I 7:1597-603.

29. Bavister BD, Squirrell JM: Mitochondrial distribution and function in oocytes and early embryos. Hum Reprod 2000:189-198.

30. Nishi Y, Takeshita T, Sato K, Araki T: Change of the mitochondrial distribution in mouse ooplasm during in vitro maturation. J Nippon Med Sch 2003, 70:408-4I5.

3I. Eichenlaub-Ritter U, Vogt E, Yin H, Gosden R: Spindles, mitochondria and redox potential in ageing oocytes. Reprod Biomed Online 2004, 8:45-58.

32. Van Blerkom J: Mitochondria in human oogenesis and preimplantation embryogenesis: engines of metabolism, ionic regulation and developmental competence. Reproduction 2004, I 28:269-280.

33. Vandevoort CA, Baughman WL, Stouffer RL: Comparison of different regimens of human gonadotropins for superovulation of rhesus monkeys: ovulatory response and subsequent luteal function. J In Vitro Fert Embryo Transf 1989, 6:85-91.

34. Duffy DM, Dozier BL, Seachord CL: Prostaglandin dehydrogenase and prostaglandin levels in periovulatory follicles: implications for control of primate ovulation by prostaglandin E2. J Clin Endocrinol Metab 2005, 90: I02 I- 1027. 
35. Baka SG, Toth TL, Veeck LL, Jones HW Jr, Muasher SJ, Lanzendorf SE: Evaluation of the spindle apparatus of in-vitro matured human oocytes following cryopreservation. Hum Reprod 1995, 10:1816-1820.

36. Trounson A, Anderiesz C, Jones GM, Kausche A, Lolatgis N, Wood C: Oocyte maturation. Hum Reprod 1998:52-62.

37. Schramm RD, Bavister BD: A macaque model for studying mechanisms controlling oocyte development and maturation in human and non-human primates. Hum Reprod 1999, I 4:2544-2255.

38. Borman SM, Chaffin CL, Schwinof KM, Stouffer RL, Zelinski-Wooten MB: Progesterone promotes oocyte maturation, but not ovulation, in nonhuman primate follicles without a gonadotropin surge. Biol Reprod 2004, 71:366-373.

39. Eichenlaub-Ritter U, Betzendahl I: Chloral hydrate induced spindle aberrations, metaphase $I$ arrest and aneuploidy in mouse oocytes. Mutagenesis 1995, 10:477-486.

40. Yin H, Baart E, Betzendahl I, Eichenlaub-Ritter U: Diazepam induces meiotic delay, aneuploidy and predivision of homologues and chromatids in mammalian oocytes. Mutagenesis 1998, I3:567-580.

4I. Chian RC, Gulekli B, Buckett WM, Tan SL: Priming with human chorionic gonadotropin before retrieval of immature oocytes in women with infertility due to the polycystic ovary syndrome. N Engl J Med I999, 34I:1624-1626.

42. Child TJ, Phillips SJ, Abdul-Jalil AK, Gulekli B, Tan SL: A comparison of in vitro maturation and in vitro fertilization for women with polycystic ovaries. Obstet Gynecol 2002, 100:665-670.

43. Coy P, Ruiz S, Romar R, Campos I, Gadea J: Maturation, fertilization and complete development of porcine oocytes matured under different systems. Theriogenology 1999, 5 I:799-8I2.

44. Osaki S, Matsumur K, Yamamoto K, Miyano T, Miyake M, Kato S: Fertilization of bovine oocytes grown in vitro. Reprod Fertil Dev 1997, 9:78I-787.

45. De La Fuente R, O'Brien MJ, Eppig JJ: Epidermal growth factor enhances preimplantation developmental competence of maturing mouse oocytes. Hum Reprod 1999, 14:3060-3068.

46. Mikkelsen AL, Smith S, Lindenberg S: Possible factors affecting the development of oocytes in in-vitro maturation. Hum Reprod 2000:11-17.

47. Luo H, Kimura K, Aoki M, Hirako M: Effect of vascular endothelial growth factor on maturation, fertilization and developmental competence of bovine oocytes. J Vet Med Sci 2002, 64:803-806.

48. Zheng P, Si W, Bavister BD, Yang J, Ding C, Ji W: I 7- beta-estradiol and progesterone improve in-vitro cytoplasmic maturation of oocytes from unstimulated prepubertal and adult rhesus monkeys. Hum Reprod 2003, 18:2137-2।44.

49. Demeestere I, Gervy C, Centner J, Devreker F, Englert Y, Delbaere A: Effect of insulin-like growth factor-I during preantral follicular culture on steroidogenesis, in vitro oocyte maturation, and embryo development in mice. Biol Reprod 2004, 70:1664-1669.

50. Li Y, Chen Z, Zhao L, Li M, Ma S, Wang L, Hu J: Influence of epidermal growth factor and gonadotrophin on the in vitro maturation of human oocytes. Zhonghua Nan Ke Xue 2004, 10:257-259.

51. Brown JR, Modell E, Obasaju M, King YK: Natural cycle in-vitro fertilization with embryo cryopreservation prior to chemotherapy for carcinoma of the breast. Hum Reprod 1996, II:197-199.

52. Gosden RG: Prospects for oocyte banking and in vitro maturation. J Natl Cancer Inst Monog 2005, 34:60-63.

53. Battaglia DE, Goodwin P, Klein NA, Soules MR: Influence of maternal age on meiotic spindle assembly in oocytes from naturally cycling women. Hum Reprod 1996, I I:2217-2222.

54. Volarcik K, Sheean L, Goldfarb J, Woods L, Abdul-Karim FW, Hunt P. The meiotic competence of in-vitro matured human oocytes is influenced by donor age: evidence that folliculogenesis is compromised in the reproductively aged ovary. Hum Reprod 1998, 13:154-160.

55. LeMaire-Adkins R, Radke K, Hunt PA: Lack of checkpoint control at the metaphase/anaphase transition: a mechanism of meiotic nondisjunction in mammalian females. J Cell Biol 1997, 139:1611-1619.
56. Barritt JA, Brenner CA, Cohen J, Matt DW: Mitochondrial DNA rearrangements in human oocytes and embryos. Mol Hum Reprod 1999, 5:927-933.

57. Liu L, Trimarchi JR, Keefe DL: Involvement of mitochondria in oxidative stress-induced cell death in mouse zygotes. Biol Reprod 2000, 62: 1745-53.

58. Sanfins A, Lee GY, Plancha CE, Overstrom EW, Albertini DF: Distinctions in meiotic spindle structure and assembly during in vitro and in vivo maturation of mouse oocytes. Biol Reprod 2003, 69:2059-2067.

59. Tokura T, Noda Y, Goto Y, Mori T: Sequential observation of mitochondrial distribution in mouse oocytes and embryos. Assist Reprod Genet 1993, 10:417-426.

60. Van Blerkom J, Davis P, Alexander S: Differential mitochondrial distribution in human pronuclear embryos leads to disproportionate inheritance between blastomeres: relationship to microtubular organization, ATP content and competence. Hum Reprod 2000, 15:262I-2633.

61. Stojkovic M, Machado SA, Stojkovic P, Zakhartchenko V, Hutzler P, Goncalves $\mathrm{PB}$, Wolf $\mathrm{E}$ : Mitochondrial distribution and adenosine triphosphate content of bovine oocytes before and after in vitro maturation: correlation with morphological criteria and developmental capacity after in vitro fertilization and culture. Biol Reprod 200I, 64:904-909.

62. Squirrell JM, Schramm RD, Paprocki AM, Wokosin DL, Bavister BD: Imaging mitochondrial organization in living primate oocytes and embryos using multiphoton microscopy. Microsc Microanal 2003, 9:190-201.

Publish with Bio Med Central and every scientist can read your work free of charge

"BioMed Central will be the most significant development for disseminating the results of biomedical research in our lifetime. "

Sir Paul Nurse, Cancer Research UK

Your research papers will be:

- available free of charge to the entire biomedical community

- peer reviewed and published immediately upon acceptance

- cited in PubMed and archived on PubMed Central

- yours - you keep the copyright

Submit your manuscript here:

http://www.biomedcentral.com/info/publishing_adv.asp
BioMedcentral 